\title{
EFEITO DE DOSES DE POTÁSSIO E DA FREQÜÊNCIA DE IRRIGAÇÃO NA PRODUÇÃO DA ALFACE-AMERICANA EM AMBIENTE PROTEGIDO
}

\author{
MARCIO KOETZ ${ }^{1}$, GILBERTO COELHO ${ }^{2}$, CLAUDIONOR C. DA COSTA ${ }^{3}$, \\ EDSON P. LIMA ${ }^{4}$, ROVILSON J. DE SOUZA ${ }^{5}$
}

\begin{abstract}
RESUMO: A produção da alface tipo americana em ambiente protegido, aliada ao emprego de práticas de manejo de irrigação e adubação, pode contribuir para o aumento da produtividade e expansão da cultura na região de Lavras - MG. Em uma estufa modelo capela, foi realizado um experimento com o objetivo de avaliar o efeito de freqüências de irrigação e de doses de potássio sobre a produtividade da alface-americana e a eficiência do uso da água. $\mathrm{O}$ experimento foi composto pelos seguintes tratamentos de turnos de rega: (P1) - irrigação diária; (P2) - irrigação de dois em dois dias; (P3) - irrigação de três em três dias, e (P4) - irrigação de quatro em quatro dias. Nas parcelas subdivididas, foram aplicadas quatro doses de cloreto de potássio, via fertirrigação: (D1) - $100 \mathrm{~kg}$ de $\mathrm{KCl} \mathrm{ha}^{-1}$; (D2) - $150 \mathrm{~kg} \mathrm{de} \mathrm{KCl} \mathrm{ha}^{-1}$; (D3) - $200 \mathrm{~kg} \mathrm{de} \mathrm{KCl} \mathrm{ha}^{-1}$, e (D4) - $250 \mathrm{~kg} \mathrm{de}$ $\mathrm{KCl} \mathrm{ha}{ }^{-1}$. As variáveis avaliadas foram a produtividade de alface e a eficiência do uso da água, ou seja, a produtividade por milímetro de água aplicado. Concluiu-se que a maior produtividade

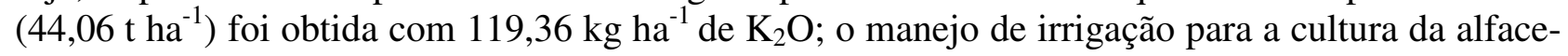
americana em ambiente protegido poderá ser realizado com intervalo entre irrigações de quatro dias, e com o aumento dos intervalos houve aumento da eficiência de uso da água de irrigação.
\end{abstract}

PALAVRAS-CHAVE: irrigação, fertirrigação, manejo de irrigação.

\section{EFFECT OF POTASSIUM DOSES AND IRRIGATION FREQUENCY IN THE PRODUCTION OF THE AMERICAN LETTUCE IN GREENHOUSE CONDITION}

\begin{abstract}
The production of the American lettuce type in greenhouse conditions using irrigation and fertilization, may contribute for the yield increase and expansion of the culture in the region of Lavras - MG, Brazil. In a greenhouse model chapel was carried out an experiment with the objective of evaluating the effects of irrigation frequencies and potassium doses on the yield of the American lettuce and the water use efficiency. The experiment was composed by the following treatments of irrigation frequency: (P1) - daily irrigation; (P2) - every other day irrigation; (P3) three in three days irrigation, and (P4) - four in four days irrigation. In the split plots four doses of potassium chloride $\left(60 \%\right.$ of $\left.\mathrm{K}_{2} \mathrm{O}\right)$ were applied, by fertigation: (D1) - $100 \mathrm{~kg} \mathrm{KCl} \mathrm{ha}{ }^{-1}$; (D2) $150 \mathrm{~kg} \mathrm{KCl} \mathrm{ha}^{-1}$; (D3) - $200 \mathrm{~kg} \mathrm{KCl} \mathrm{ha}^{-1}$, and (D4) - $250 \mathrm{~kg} \mathrm{KCl} \mathrm{ha}^{-1}$. The variables evaluated were lettuce productivity in tons for hectare and water efficiency use, that is, the productivity for mm of water applied. It was possible to conclude that the highest productivity $\left(44,06 \mathrm{t} \mathrm{ha}^{-1}\right)$ was obtained with the dose of the $119,36 \mathrm{~kg}$ of $\mathrm{K}_{2} \mathrm{O} \mathrm{ha}{ }^{-1}$; the irrigation management for the American lettuce culture, in greenhouse conditions of Lavras can be carried out in irrigation interval of four days. The treatments with higher irrigation intervals presented greater water use efficiency.
\end{abstract}

KEYWORDS: irrigation, fertigation, water management.

\footnotetext{
${ }^{1}$ Doutorando em Engenharia Agrícola (Irrigação e Drenagem), R. Saturnino de Pádua, 45, Centro, Lavras - MG, Fone: (0XX35) 3822.2214, marciokoetz@yahoo.com.br.

${ }^{2}$ Eng $^{\mathrm{o}}$ Agrícola, Doutor em Irrigação e Drenagem, UFLA - MG.

${ }^{3}$ Doutorando em Irrigação e Drenagem ,UFLA - MG.

${ }^{4}$ Eng ${ }^{\mathrm{o}}$ Agrícola, Doutor em Irrigação e Drenagem, UFLA - MG.

${ }^{5}$ Eng ${ }^{0}$ Agrônomo, Professor Titular do Departamento de Agricultura, UFLA - MG.

Recebido pelo Conselho Editorial em: 25-10-2004
}

Aprovado pelo Conselho Editorial em: 27-10-2006 


\section{INTRODUÇÃO}

Em relação ao mercado brasileiro, a alface é a principal folhosa, tanto em termos de produção quanto de consumo. A região Sudeste é responsável por $65 \%$ da produção, destacando-se São Paulo e Minas Gerais (IBGE, 1996). O volume comercializado anualmente na CEAGESP (média de 1998 a 2001) é de aproximadamente 22.028 toneladas (AGRIANUAL, 2003). Em 1997, a McDonald's (rede fast food) consumiu 2.300 toneladas da alface tipo americana (QUALIDADE É FUNDAMENTAL, 1998). A alface é uma cultura exigente em água, sendo o manejo adequado da irrigação importante não apenas por suprir as necessidades hídricas das plantas, mas também por minimizar problemas com doenças e lixiviação de nutrientes, bem como gastos desnecessários com água e energia.

A região do sul de Minas apresenta clima favorável ao cultivo de alface durante o ano todo e localiza-se próxima a dois grandes centros consumidores (Belo Horizonte e São Paulo). Por esse motivo, produtores da região estão viabilizando técnicas que possibilitem maior produtividade e qualidade dos produtos. Dentre as técnicas utilizadas, o cultivo em ambiente protegido mostra-se viável pela possibilidade de controle dos fatores ambientais, podendo, assim, haver maior produtividade e produtos de melhor qualidade, além de amenizar problemas relacionados a pragas e doenças.

A fertirrigação é o processo de aplicação simultânea de água e fertilizantes às plantas, por meio de sistema de irrigação, trazendo como vantagens maior eficiência e economia de fertilizantes e mão-de-obra, aplicação da dose correta, na profundidade adequada, possibilidade de veiculação de diversos tipos de produtos, menor risco, maior facilidade de aplicação e versatilidade de uso em qualquer tipo de solo (MAROUELLI et al., 1996).

A prática de fertirrigação tem-se mostrado mais eficiente no fornecimento de nutrientes para diversas culturas, com uma série de vantagens sobre a forma tradicional (ALVARENGA, 1999). Embora a fertirrigação seja uma técnica utilizada com sucesso em vários países do mundo, sendo poucos os trabalhos desenvolvidos nessa área no Brasil, citam-se alguns recentes com alface (BUENO, 1998; ALVARENGA, 1999; MOTA, 1999).

Apesar de absorver quantidades relativamente pequenas de nutrientes comparadas com outras culturas, devido ao seu ciclo curto (50 a 70 dias, em função de cultivares, épocas e locais de cultivo), a alface pode ser considerada como exigente em nutrientes, principalmente na fase final do ciclo (KATAYAMA, 1993).

O potássio, segundo FAQUIN (1994), é, de maneira geral, o segundo nutriente mais exigido pelas culturas depois do nitrogênio. Entre as várias funções que exerce nas plantas, citam-se: melhor eficiência de uso da água, em conseqüência do controle da abertura e da fechamento dos estômatos, maior translocação de carboidratos produzidos nas folhas para os outros órgãos das plantas, maior eficiência enzimática e melhoria da qualidade comercial da planta (YAMADA, 1995; MALAVOLTA et al., 1997).

Em agricultura irrigada, a elevação e a determinação dos níveis da eficiência do uso da água (EUA) são bastante complexos e requerem conhecimentos e considerações interdisciplinares. Todavia, DINAR (1993) menciona que existem meios para se elevarem os valores de EUA, destacando-se, entre esses, o manejo adequado da irrigação. Quando a eficiência do uso da água é determinada a partir da quantidade de água aplicada, DINAR (1993) e LETEY (1993) destacam sua redução, porém sem diminuição da produção, como forma de aumentar a EUA.

HAMADA \& TESTEZLAF (1995), analisando a eficiência do uso da água em função da lâmina total aplicada por gotejamento, na produção comercial da alface, em condições de campo, observaram que os maiores valores de eficiência do uso da água foram obtidos com as menores lâminas de água. Diante dessas exposições, desenvolveu-se o presente trabalho com o objetivo de avaliar os efeitos de lâminas de irrigação associadas a frequiências de irrigação e de doses de potássio, sobre a produtividade e a eficiência de uso da água de irrigação sobre a cultura da alfaceamericana. 


\section{MATERIAL E MÉTODOS}

O experimento foi conduzido em casa de vegetação, situada no setor de Olericultura do Departamento de Agricultura da Universidade Federal de Lavras, UFLA, no período compreendido entre os meses de abril e junho de 2003. A UFLA situa-se no município de Lavras, sul de Minas Gerais, que está numa altitude média de $910 \mathrm{~m}, 21^{\circ} 14^{\prime}$, latitude sul e $45^{\circ} 00^{\prime}$, longitude oeste.

$\mathrm{O}$ experimento foi instalado em estufa modelo capela, com dimensões de 10 x $32 \mathrm{~m}$, com altura na parte central de 3,5 m e pé-direito de $2,0 \mathrm{~m}$, revestida na parte superior com filme plástico transparente, aditivado anti-UV, de $150 \mu \mathrm{m}$ de espessura, e nas laterais com tela antiafídeos. Foi utilizada a alface (Lactuca sativa L.) tipo americana cv. Raider.

\section{Delineamento experimental e tratamentos}

Foi empregado o delineamento em blocos casualizados, com parcelas subdivididas, sendo utilizados 16 tratamentos e quatro repetições. Nas parcelas, foram aplicados os tratamentos de turnos de rega: (P1) - irrigação diária; (P2) - irrigação de dois em dois dias; (P3) - irrigação de três em três dias, e (P4) - irrigação de quatro em quatro dias. Nas subparcelas, foram aplicadas quatro doses de cloreto de potássio $\left(60 \%\right.$ de $\left.\mathrm{K}_{2} \mathrm{O}\right)$, via fertirrigação: (D1) - $100 \mathrm{~kg} \mathrm{KCl} \mathrm{ha}^{-1}$; (D2) - $150 \mathrm{~kg}$ $\mathrm{KCl} \mathrm{ha}{ }^{-1}$; (D3) - $200 \mathrm{~kg} \mathrm{KCl} \mathrm{ha}^{-1}$, e (D4) - $250 \mathrm{~kg} \mathrm{KCl} \mathrm{ha}^{-1}$.

A lâmina aplicada foi determinada indiretamente com base nas eqs.(1) a (5), e, para tal, instalou-se uma bateria de dois tensiômetros (um a $0,10 \mathrm{~m}$ e outro a $0,25 \mathrm{~m}$ de profundidade) em cada uma das 16 subparcelas do bloco III, totalizando 32 tensiômetros. Em virtude do desenvolvimento radicular da alface, nos primeiros 30 dias, foram utilizados para o manejo da irrigação, apenas os tensiômetros instalados a $0,10 \mathrm{~m}$. Após esse período, foram incluídas no manejo as leituras dos tensiômetros instalados a $0,25 \mathrm{~m}$. As leituras nos tensiômetros foram feitas com tensímetro de punção. Os tensiômetros foram posicionados a $0,15 \mathrm{~m}$ da linha lateral de irrigação e a 0,15 $\mathrm{m}$ da linha de plantas, ficando $0,10 \mathrm{~m}$ distanciados entre si em cada bateria.

Os valores das leituras nos tensiômetros foram convertidos em potencial matricial de água no solo $\left(\Psi_{\mathrm{m}}\right)$, utilizando a eq.(1).

$$
\psi_{\mathrm{m}}=\mathrm{L}-0,098 \mathrm{~h}
$$

em que,

$\Psi_{\mathrm{m}}$ - tensão de água no solo, $\mathrm{kPa}$;

$\mathrm{L}$ - leitura no tensímetro transformada em $\mathrm{kPa}$, sinal positivo, e

$\mathrm{h}$ - altura desde o ponto da leitura no tensiômetro até o centro da cápsula porosa, $\mathrm{cm}$.

Em seguida, foram determinados os respectivos valores de umidade nas camadas, utilizando a eq.(2).

$$
\theta=\theta \mathrm{r}+(\theta \mathrm{s}-\theta \mathrm{r})\left[1+\left(|\alpha| \psi_{\mathrm{m}}\right)^{\mathrm{n}}\right]^{-\mathrm{m}}
$$

em que,

$\theta$ - umidade volumétrica, $\mathrm{cm}^{3} \mathrm{~cm}^{-3}$, associada a um potencial mátrico;

$\theta \mathrm{s}$ - umidade volumétrica de saturação, $\mathrm{cm}^{3} \mathrm{~cm}^{-3}$;

$\theta \mathrm{r}$ - umidade volumétrica residual, $\mathrm{cm}^{3} \mathrm{~cm}^{-3}$, obtida a 15 atmosferas, e

$\mathrm{n}, \mathrm{m}$ e $\alpha$ - parâmetros empíricos do modelo (constantes que dependem do solo).

A partir dos valores de umidade no momento de irrigação e da umidade na capacidade de campo, determinou-se a lâmina líquida de irrigação, como mostra a eq. (3).

$$
\mathrm{LL}=\left(\theta_{\mathrm{cc}}-\theta_{\text {atual }}\right) \mathrm{Z}
$$

em que,

LL - lâmina líquida de irrigação, mm;

$\theta_{\mathrm{cc}}$ - umidade na capacidade de campo, $\mathrm{cm}^{3} \mathrm{~cm}^{-3}$;

$\theta_{\text {atual }}$ - umidade no momento da irrigação, $\mathrm{cm}^{3} \mathrm{~cm}^{-3}$, e 
$\mathrm{Z}$ - profundidade do sistema radicular estratificada em duas subcamadas, 0-20 $\mathrm{cm}$ e 20-30 $\mathrm{cm}$.

Com o valor da lâmina líquida e da eficiência de irrigação, pôde-se, então, calcular o valor da lâmina bruta por meio da eq.(4). A eficiência de irrigação utilizada foi de $90 \%$, conforme BERNARDO et al. (2005).

$$
\mathrm{LB}=\frac{\mathrm{LL}}{\mathrm{EI}}
$$

em que,

LB - lâmina bruta de irrigação, mm, e

EI - eficiência de irrigação, adimensional.

O resultado da lâmina bruta de irrigação deverá ser a soma da lâmina bruta média a $10 \mathrm{~cm}$ de profundidade e a lâmina bruta média a $25 \mathrm{~cm}$ de profundidade, conforme eq.(5).

$$
\text { LBmédia }=\text { LBmédia }_{10 \mathrm{~cm}}+\text { LBmédia }_{25 \mathrm{~cm}}
$$

As parcelas experimentais possuíam dimensões de $1,20 \mathrm{~m}$ de largura por $8,40 \mathrm{~m}$ de comprimento $\left(10,08 \mathrm{~m}^{2}\right)$, e as subparcelas, $1,20 \mathrm{~m}$ de largura por $2,10 \mathrm{~m}$ de comprimento $\left(2,52 \mathrm{~m}^{2}\right)$. Foram utilizadas quatro linhas de plantas espaçadas de $0,30 \mathrm{~m}$ entre si e $0,30 \mathrm{~m}$ entre plantas, dando um total de 112 plantas por parcela. Foram consideradas úteis as plantas das linhas centrais, sendo descartadas, nessas linhas, duas plantas no início e duas no final de cada subparcela. Na Figura 1, apresenta-se o croqui de uma parcela experimental, incluindo a disposição dos tensiômetros.

Planta bordadura * Planta útil

..... Extremidade da parcela
- Tensiômetro a $10 \mathrm{~cm}$ • Tensiômetro a $25 \mathrm{~cm}$ Linha lateral de irrigação

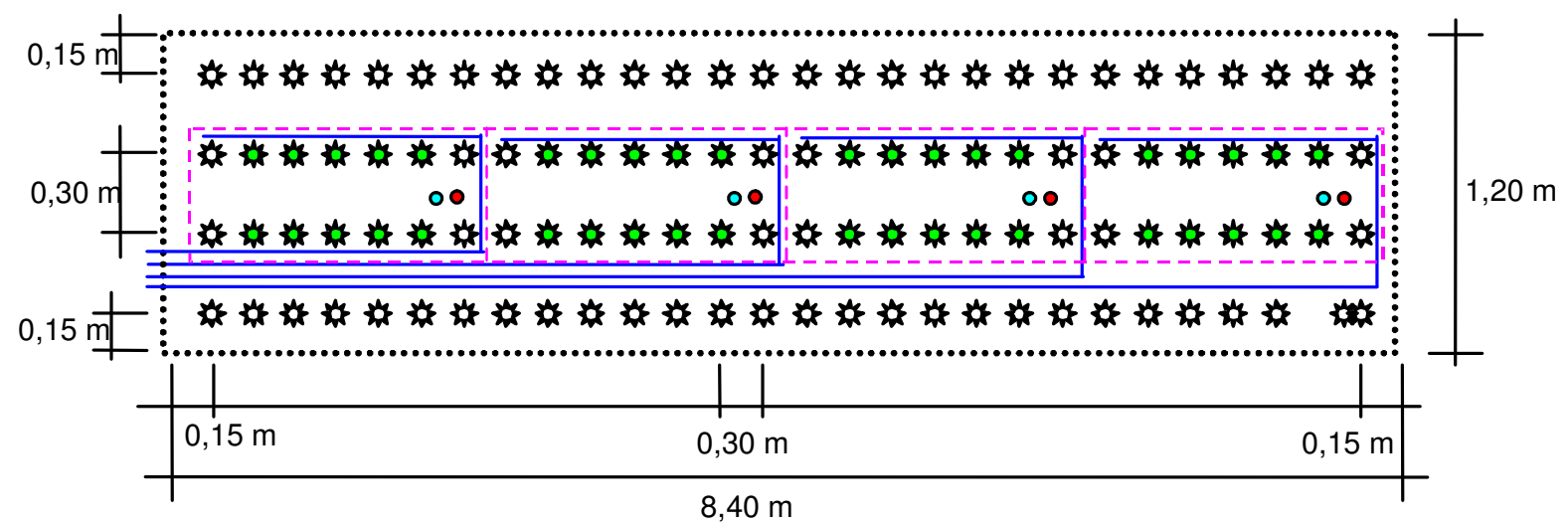

FIGURA 1. Esquema de uma parcela com o sistema de irrigação implantado e bateria de tensiômetros.

\section{Equipamento e manejo da irrigação}

Durante a fase de pegamento das mudas, as irrigações foram realizadas por microaspersão, parceladas em duas aplicações por dia. Após a fase de pegamento, foi utilizado, para a aplicação dos tratamentos, um sistema de irrigação por gotejamento, sendo os emissores com inserção sobrelinha e distanciados entre si de $0,40 \mathrm{~m}$. A linha de irrigação utilizou gotejadores do tipo botão inseridos na linha, fabricados pela empresa Plastro, modelo Katif, autocompensante (10 a 35 mca), com vazão de $2,3 \mathrm{~L} \mathrm{~h}^{-1}$.

Duas linhas de irrigação foram colocadas sobre cada subparcela (quatro fileiras de plantas), sendo cada linha entre duas fileiras. Para a determinação da uniformidade de distribuição d'água, foi utilizado o método proposto por KELLER \& KARMELI (1975), obtendo-se as vazões em quatro pontos ao longo da linha lateral, ou seja, do primeiro gotejador, do gotejador situado a $1 / 3$ 
do comprimento, do gotejador a $2 / 3$ do comprimento e do último gotejador. As linhas laterais selecionadas para a determinação, ao longo da linha de derivação, foram a primeira linha lateral, a linha lateral situada a $1 / 3$, a situada a $2 / 3$ e a última linha lateral. A uniformidade de distribuição de água (CUD) foi de $90 \%$, determinada pela eq.(6):

$$
\mathrm{CUD}=100 \frac{\mathrm{X}_{25}}{\mathrm{X}_{\mathrm{m}}}
$$

em que,

CUD - coeficiente de uniformidade de distribuição, \%;

$\mathrm{X}_{25}$ - média de $25 \%$ das vazões, com menores valores, mm, e

$\mathrm{X}_{\mathrm{m}}$ - média de todas as vazões, $\mathrm{mm}$.

\section{Parâmetros avaliados}

Foram avaliadas a produtividade da cultura $\left(\mathrm{t} \mathrm{ha}^{-1}\right)$ e a eficiência do uso da água $\left(\mathrm{g} \mathrm{m}^{-2} \mathrm{~mm}^{-1}\right)$, determinadas pela relação entre a produtividade da cultura (massa de alface) e as diferentes lâminas de água aplicadas pela irrigação [eq.(7)].

$$
\mathrm{EUA}=\frac{\mathrm{P}}{\mathrm{L}}
$$

em que,

EUA - eficiência do uso da água, $\mathrm{g} \mathrm{m}^{-2} \mathrm{~mm}^{-1}$;

$\mathrm{P}$ - produtividade, $\mathrm{g} \mathrm{m}^{-2}$, e

L - lâmina de água aplicada, mm.

\section{RESULTADOS E DISCUSSÃO}

Na Tabela 1, são mostrados os valores de lâmina acumulada, lâmina média aplicada a cada irrigação e o desvio-padrão da média, conforme respectivos tratamentos.

TABELA 1. Lâmina total de irrigação, lâmina média aplicada por irrigação e desvio-padrão da média conforme respectivos tratamentos.

\begin{tabular}{crrrr}
\hline & \multicolumn{4}{c}{ Intervalo entre Irrigações (dias) } \\
\cline { 2 - 5 } & \multicolumn{1}{c}{1} & \multicolumn{1}{c}{3} & \multicolumn{1}{c}{4} \\
\hline Lâmina total $(\mathrm{mm})$ & 243,78 & 225,84 & 193,21 & 164,48 \\
Lâmina média (mm) & 5,95 & 9,41 & 12,88 & 13,71 \\
Desvio-padrão (mm) & 2,96 & 2,88 & 1,74 & 3,78 \\
C.V. (\%) & 49,74 & 30,61 & 13,51 & 27,57 \\
\hline
\end{tabular}

O manejo da irrigação realizado por meio de tensiômetros determinou lâminas resultantes diferentes, devido a que, ao aumentar-se o intervalo entre irrigações e com a evapotranspiração, a água ficou retida no solo sob tensões que fizeram as plantas não consumirem a mesma quantidade que no tratamento irrigado diariamente. A maior lâmina total aplicada ocorreu no tratamento de irrigação diária $(243,78 \mathrm{~mm})$ e decresceu conforme o aumento do intervalo entre irrigações, sendo a menor lâmina total aplicada de 164,48 mm no tratamento com irrigação a cada quatro dias. Já a lâmina média aplicada por irrigação aumentou com o aumento do intervalo entre irrigações, sendo de $5,95 \mathrm{~mm}$ no tratamento de irrigação diária e de $13,71 \mathrm{~mm}$ no tratamento com irrigação a cada quatro dias. Pode-se verificar que o desvio-padrão da média variou de 1,74 a 3,78 mm, com coeficiente de variação de 13,51 a 49,74. Na Tabela 2, pode ser observado o resultado da análise de variância contendo a soma de quadrados dos parâmetros produtividade e eficiência de irrigação.

Por meio da análise de variância, verificou-se que a produtividade foi influenciada apenas pelas doses de potássio, apresentando significância a 5\% de probabilidade. A eficiência no uso da água foi afetada significativamente tanto pelas lâminas ( $1 \%$ de probabilidade) quanto pelas doses 
de potássio (5\%); todavia, não será discutido o efeito das doses de potássio, porque, no que diz respeito à eficiência no uso da água de irrigação, é interessante inferir sobre qual lâmina proporcionou melhor eficiência. A interação entre lâminas e doses não afetou de forma significativa os parâmetros estudados, conforme Tabela 2.

TABELA 2. Resumo da análise de variância, contendo a soma de quadrados dos parâmetros produtividade e eficiência de irrigação.

\begin{tabular}{cccc}
\hline FV & GL & SQ Produtividade & SQ Eficiência \\
\hline Blocos & 3 & $6,97^{\mathrm{ns}}$ & $141,33^{\mathrm{ns}}$ \\
Freqüência de irrigação & 3 & $9,72^{\mathrm{ns}}$ & $909,01^{* *}$ \\
Resíduo 1 & 9 & $14,56^{*}$ & 330,86 \\
Doses de Potássio & 3 & $7,08^{*}$ & $176,12^{*}$ \\
Freq. x Doses & 9 & $8,45^{\mathrm{ns}}$ & $239,51^{\mathrm{ns}}$ \\
Resíduo 2 & 36 & 21,46 & 547,06 \\
\hline Total & 63 & $68,26^{2}$ & $2.343,89$ \\
\hline C.V.1 (\%) & & 21,01 & 20,38 \\
C.V.2 $(\%)$ & & 12,75 & 13,10 \\
\hline
\end{tabular}

${ }^{\overline{\mathrm{ns}}}$ não-significativo; ${ }^{*}$ significativo a $5 \%$ de probabilidade; ${ }^{* *}$ significativo a $1 \%$ de probabilidade.

Mesmo não havendo diferença significativa entre as frequiências de irrigação, foi possível verificar que houve tendência de aumento da produtividade para o intervalo entre irrigações de um a dois dias, com 47,3 $\mathrm{t} \mathrm{ha}^{-1}$, decrescendo até o intervalo de quatro dias, conforme Tabela 3.

TABELA 3. Médias de produtividade da alface-americana, em função do intervalo entre irrigações.

\begin{tabular}{ccccc}
\hline & \multicolumn{4}{c}{ Intervalo entre Irrigações (dias) } \\
\cline { 2 - 5 } & 1 & 2 & 3 & 4 \\
\hline Produtividade $\left(\mathrm{t} \mathrm{ha}^{-1}\right)$ & 41,3 & 47,3 & 42,0 & 40,1 \\
\hline
\end{tabular}

A produtividade em função das doses de potássio apresentou modelo de regressão quadrático; logo, foi possível identificar que a dose que proporcionou a melhor produtividade (dose ótima), foi de $119,36 \mathrm{~kg} \mathrm{ha}^{-1}$ de potássio $\left(\mathrm{K}_{2} \mathrm{O}\right)$ ou $198,93 \mathrm{~kg} \mathrm{ha}^{-1}$ de cloreto de potássio $(\mathrm{KCl})$, para produtividade de 44,06 $\mathrm{t} \mathrm{ha}^{-1}$, conforme Figura 2.

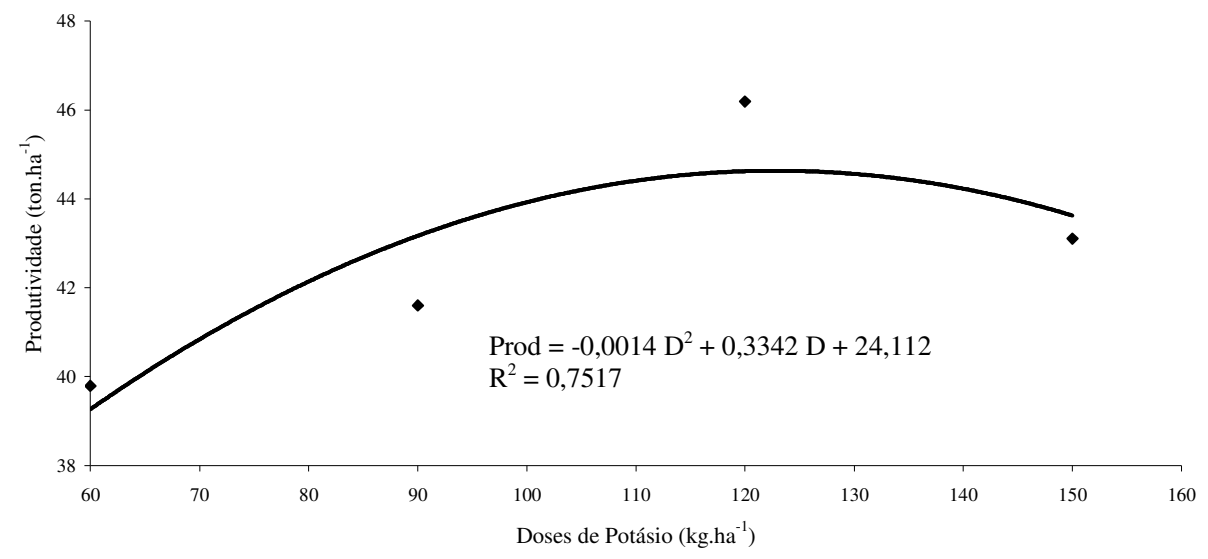

FIGURA 2. Produtividade da alface em função de doses de potássio.

O fator lâminas aplicadas afetou estatisticamente a eficiência do uso da água. Na Figura 3, mostra-se a eficiência no uso da água, em $\mathrm{g} \mathrm{m}^{-2} \mathrm{~mm}^{-1}$. 


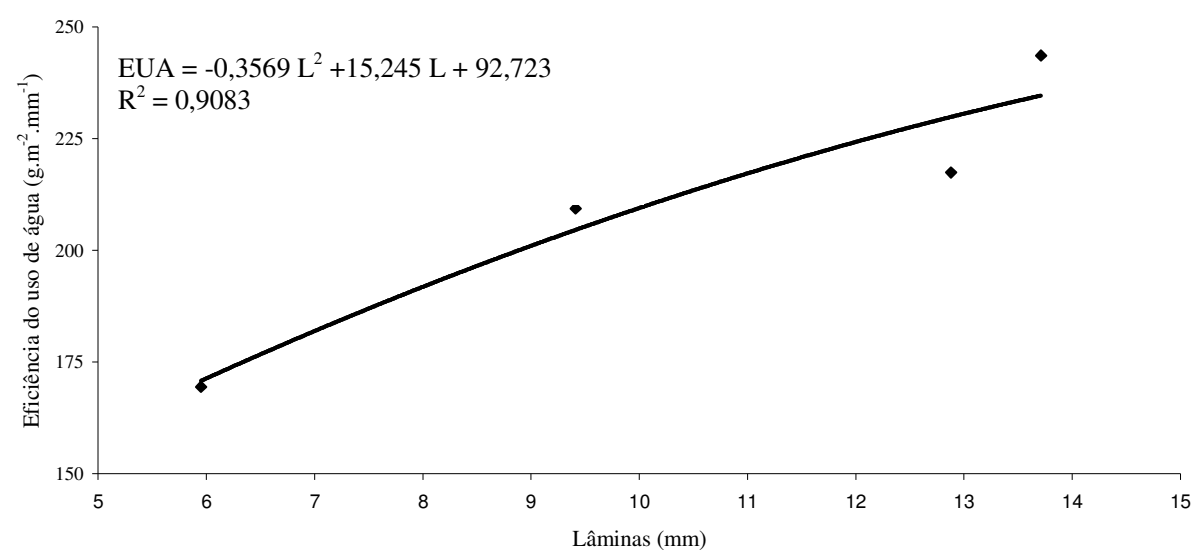

FIGURA 3. Eficiência do uso da água em função das lâminas aplicadas.

Analisando a Figura 3, pode-se verificar que a eficiência de uso da água em função das lâminas médias aplicadas forneceu ajuste quadrático; todavia, ao se determinar a lâmina ótima, nota-se que essa se apresenta além das lâminas estudadas $(21,36 \mathrm{~mm}$ e eficiência de $255,52 \mathrm{~g} \mathrm{~m}^{2} \mathrm{~mm}^{-1}$ ); isso ocorreu porque, à medida que se aumenta a lâmina média aplicada, aumenta-se o intervalo entre irrigações, e a lâmina total aplicada diminui. Já que não houve diferença significativa do fator lâminas de irrigação sobre a produtividade, reduções consideráveis na lâmina aplicada reduziram pouco a produtividade, fazendo com que os tratamentos que receberam menor quantidade de água se tornassem mais eficientes no uso da água de irrigação. Comportamento semelhante também foi observado por HAMADA \& TESTEZLAF (1995) com a cultura da alface.

\section{CONCLUSÕES} $\mathrm{K}_{2} \mathrm{O}$.

A maior produtividade de alface-americana $\left(44,06 \mathrm{t} \mathrm{ha}^{-1}\right)$ foi obtida com 119,36 $\mathrm{kg} \mathrm{ha}^{-1} \mathrm{de}$

O manejo de irrigação para a alface-americana em ambiente protegido, nas condições de Lavras- MG, poderá ser realizado com intervalo entre irrigações de quatro dias e com $60 \mathrm{~kg} \mathrm{ha}^{-1} \mathrm{de}$ $\mathrm{K}_{2} \mathrm{O}$, sem comprometer a produtividade.

$\mathrm{O}$ tratamento com intervalo entre irrigações de quatro dias apresentou maior eficiência do uso da água de irrigação.

\section{REFERÊNCIAS}

ALVARENGA, M.A.R. Crescimento, teor e acúmulo de nutrientes em alface-americana (Lactuca sativa $L$.) sob doses de nitrogênio aplicadas no solo e de níveis de cálcio aplicados via foliar. 1999. 117 f. Tese (Doutorado em Fitotecnia) - Universidade Federal de Lavras, Lavras, 1999.

AGRIANUAL 2002: anuário da agricultura brasileira. São Paulo: FNP Consultoria \& Comércio, 2003. p.190-2.

BERNARDO, S.; SOARES, A.A.; MANTOVANI, E.C. Manual de irrigação. 7.ed. Viçosa - MG: Universidade Federal de Viçosa, 2005. 611 p.

BUENO, C.R. Adubação nitrogenada em cobertura via fertirrigação por gotejamento para a alface-americana em ambiente protegido. 1998. 54 f. Dissertação (Mestrado em Fitotecnia) Universidade Federal de Lavras, Lavras, 1998.

DINAR, A. Economic factors and opportunities as determinates of water use efficiency in agriculture. Irrigation Science, Beer Sheva, v.14, n.2, p.47-52, 1993.

FAQUIM, V. Nutrição mineral de plantas. Lavras: FAEPE, 1994. p.118-25. Apostila do curso de especialização - Pós-Graduação "Lato Sensu” Solos e Meio Ambiente. 
HAMADA, E.; TESTEZLAF, R. Desenvolvimento e produtividade da alface submetida a diferentes lâminas de água através da irrigação por gotejamento. Pesquisa Agropecuária Brasileira, Brasília, v.30, n.9, p.1201-9, set. 1995.

KELLER, J.; KARMELI, D. Trickle irrigation design. Glendora: Rain Bird Sprinkler Manufacturing Corporation, 1975. 133 p.

QUALIDADE é fundamental. Circuito Agrícola, São Paulo, n.3, p.6-7, jul. 1998.

KATAYAMA, M. Nutrição e adubação de alface, chicória e almeirão. In: FERREIRA, M.E.;

CASTELLANE, P.D.; CRUZ, M.C.P. da. Nutrição e adubação de hortaliças. Piracicaba: Potafos, 1993. p.141-8.

LETEY, J. Relationship between salinity and efficient water use. Irrigation Science, Riverside, v.14, n.2, p.75-84, 1993.

MALAVOLTA, E.; VITTI, G.C.; OLIVEIRA, S. Avaliação do estado nutricional das plantas: princípios e aplicações. 2.ed. Piracicaba: POTAFÓS, 1997. 319 p.

MAROUELLI, W.A.; SILVA, W.L.C.; SILVA, H.R. Manejo da irrigação em hortaliças. Brasília: EMBRAPA/SPI, 1996. 72 p.

MOTA, J.H. Efeito do cloreto de potássio via fertirrigação na produção de alface-americana em cultivo protegido. 1999. 46 f. Dissertação (Mestrado em Fitotecnia)- Universidade Federal de Lavras, Lavras 1999.

YAMADA, T. Potássio: funções na planta, dinâmica no solo, adubos e adubação potássica. Uberlândia: UFU, 1995. notas de aula. 